\title{
Perennial Water Crisis in Ghana: Effects on Girl-Child Education
}

\author{
Mr. Baba Iddrisu Musah \\ University of Bergen, Norway \\ Email: binculcate2000@yahoo.com
}

\section{Doi:10.5901/mjss.2013.v4n13p193}

\begin{abstract}
Water is undoubtedly an indispensable resource. It is an essential resource for both man and industry. This makes access to water, especially potable water, one of the indicators of human development. Yet, access to water remains a critical challenge to many people, especially people of the developing world. Lack of access to water affects people in a variety of domains, including the educational domain. Using the mixed research design, but largely basic percentages, this paper examines how lack of access to water in the Tamale Metropolis in Ghana affects the education of the girl-child at the Junior High School level. The paper illustrates among others that water hauling activities by girls in the metropolis, in the wake of crisis negatively impacts their education.
\end{abstract}

Keywords: Water, girl-child, education, performance, Ghana

\section{Introduction}

Education is undoubtedly one of the essential tools for development. It is an important resource which many nations crave for in their efforts to catch up with other nations which have used education as a flagship to development. Thus, it is often said that education is a prerequisite to development. Based on these, the international community place emphasis on education; considering it as a fundamental human right which every human person should not be denied. Thus, there are international conventions which place emphasis on people's rights to education. For example, the Universal Declaration of Human Rights (1948) often considered as the brainchild of all human rights, notes in part that everyone has the right to education. It also emphasizes that education, at least from the basic and fundamental level, shall be free. It should also be directed toward the full development of the human personality and strengthen respect for human rights.

Though, the 1948 human rights framework emphasizes education entitlement to all manner of persons, subsequent frameworks, having identified children as people within whom future development rests, in addition to their vulnerabilities, lay emphasis on the fundamental need for children's education. For example, described as the mother and flagship of all human rights provisions and standards for children, the Convention on the Rights of the Child (CRC) provides a broader and detailed framework on children's rights to education. For instance, Article 29 of the CRC stipulates that the education of children shall be directed towards the development of the child's personality, talents and mental and physical abilities to their fullest potentials possible. This Article (Article 29) emphasizes the kind of education that would prepare children for active adult lives in a free society and foster respect for their parents, their own cultural identity, language and values, and for the cultural background and values of others.

Ghana is noted to be the first country to have ratified the CRC. To show its commitments to the intent and purposes of the CRC, among other factors, Ghana has over the years shown, in both policy and practices its desire to provide education to its citizens. It the area of laws for instance, Article 25 of the 1992 Constitution of Ghana guarantees children's right to education. Article 28 of the constitution also mandates Ghana's Legislative Assembly to enact laws as are necessary to ensure the rights of children, including the right to education. To practically realize the objectives which these national legislations contain, the Constitution also guarantees Free Compulsory Universal Education (FCUBE) which aims at making basic education free and accessible to all children.

\subsection{Problem Statement}

UNICEF (2012), highlighting the successes chalked by Ghana in the education sector notes that Ghana deserves praise. It particularly points out that the abolition of school fees and the provision of assistance to schools through the "capitation 
grant" since 2005 have had a significant impact on enhancing school enrolment while at the same time narrowing the gender gap in education among Ghanaian children. The study by UNICEF further emphasizes that more than $80 \%$ of children in Ghana are enrolled and staying in primary school. This percentage, according to UNICEF, is far ahead of most other countries in sub-Saharan Africa. Despite achieving this important mark, access to education still remains a challenge to many children in Ghana. The Ghana Demographic and Health Survey for instance notes that an estimated 850,000 children aged 6-11 years were out of school in 2008.

Even though both boys and girls constitute non-enrolled or out of school children, studies have shown that girls most often make up the greater numbers. Several factors have been identified as being responsible for this trend. Sutherland-Addy (2008) for example notes that in Ghana children of the poor (while the gap in school attendance rate between rich and poor is decreasing, children from the poorest households are still three times more likely to be out of school than wealthy children, UNICEF, 2012), particularly girls have a lower completion rate, are less likely to have a passing grade at the secondary level and more likely to drop out. Also, research work in Kenya and Ghana show that girls are more likely than boys to drop out of school because of negative attitudes and discrimination (Lloyd, Mensch and Clark, 1998). Evidence again show that girls are withheld from school to attend to younger siblings, to earn wages, to do household choices or farm work (Herz \& Sperling, 2004). Other well known factors such as the dependence of the family and particularly mothers on the labour of girls in poor families as well as the tendency for girls to be used as domestic servants in middle and upper class families are other obstacles identified by Herz and Sperling (2004).

Also, on the part of girls who are able to enroll in school, though the enrolment rates at the lower level are often high, this is not the situation in the progressive stages. UNESCO (2004) posits that the transition rate for girls from primary to secondary for instance is 65.3 percent compared to 62.6 percent for boys. Yet secondary transition rate for girls is 23 percent compared to 30 percent for boys. Tanye (2008) has grouped factors or constraints towards girl child education in Ghana to include socio-cultural barriers, economic constraints, institutional obstacles, political as well as personal factors. On socio-cultural constraints for instance, Tanye identifies barriers such as societal norms, laws, rules, beliefs, and practices as militating against females' access to education. Tanye (2008) furthermore argues that sending females to school entails direct costs, which are prohibitive to many families, particularly poor and rural families. She argues further that many adults in Ghana experience abject poverty throughout their lives. Thus, economic barriers include the direct costs of education, low-salaries, lack of men's financial support, and men's control of resources. Added to these is the existence of regional disparities on children's education with girls in the Northern Region four times more likely to be out of school than those in the other regions (UNICEF, 2012). There is also the existence of significant gender gaps in the Northern Region (UNICEF, 2012).

The factors as highlighted above are endless. This article examines the specific factor of how water hauling activities, resulting from the lack of access to water affects girl child education in Tamale, the capital of the northern region of Ghana. This is because access to water for many communities in Ghana remains one of the critical social problems confronting the modern Ghanaian state. This problem has grown to become perennial to the extent that it can best be described as an all-time ritual.

According to the 2006 United Nations Human Development Report (United Nations Development Programme, 2006), an estimated $25 \%$ of Ghanaians have no access to improved water resources. Though the lack of portable water supply affects almost all communities across Ghana, the situation in Tamale has become an unending phenomenon despite efforts to expand water supply to the people in the not too distant past. Added to this is the fact that lack of potable water places a heavy burden on women and school children. Women and children are for instance compelled to spend hours on end in search of water. This is partly because the provision of water for households in Ghana is the primary duty of women (The Women's Manifesto, 2004). The Women's Manifesto argues that most women in Ghana usually spend hours walking long distances to fetch and carry heavy loads of water every day. This has negative consequences for their time, health and education. Again, precious time that school children should be spending in the classroom for instance is used to look for water. This paper addresses three key research questions. These are (a) how is the perennial water crisis in the Tamale metropolis affecting punctuality of girls to school; (b) to what extent is the water crisis affecting regularity of girls to school?; and (d) does the perennial water crisis in the Tamale area have effects on performance of girls in school?

\section{Methodology}

The research adopted a mixture of qualitative and quantitative designs. Using both purposive and accidental sampling methods, a total number of sixty (60) female students at the Junior High School level and twenty (20) teachers/school 
authorities were sampled for the study. The later served as key informants. The accidental sampling method was particularly essential because school had just reopened and so both students' and teachers' attendance was expectedly poor. Two data collection instruments were used to collect data. These were the use of a questionnaire and an interview guide. To make room for flexibility, the questionnaire contained both open-ended and closed-ended questions. The use of the two data collection instruments enhanced some level of triangulation. Generally, once respondents were identified, the researcher first established rapport through the customary exchange of greetings followed by self introduction and the purpose of the study. They were than granted strict confidentiality and were assured that they could withdraw at any stage when necessary.

\section{Theory}

The theory for this research centered on the general notion of sex role socialization with emphasis on the specific roles of social learning theory. Sex role socialization places emphasis on the usefulness of socialization in the determination of the roles assigned to boys and girls by families/parents and other members of the society. In every society, gender is considered a critical component of one's identity right from birth. For example, how a child is welcomed and named in most societies is dependent on its gender. This is indicative of the first question typically asked when a human being enters the world, "is it a boy or a girl?" in Ghana. The newborn infant is usually welcomed with cultural expectations for the behaviour of boys or girls and these continuos throughout the entire life of the person in certain societies. Often, boys and girls are socialized to behave and to act in sex-appropriate ways. Thus gender socialization starts right from birth. As Bank (2007) notes, children learn that the world is gendered at a very young age and, soon after, develop a sense of their own gender identity. Otherwise refer to as sex role socialization; Bank (2007) explains gender socialization to involve developing beliefs about gender roles, the expectations associated with each sex group, and, also, gender identity.

Traced to the work of Albert Bandura, social learning theory focuses on learning in terms of stimulus and response. This approach, according to Banks (2007) suggests that children develop sex-typed behaviors because other people reinforce behaviors that conform to expectations for their sex group and do not reinforce nonconforming behaviors. Within the family for example, Banks argues that parents, as agents of socialization, interact with boys and girls in ways that reinforce sex-typed behaviors and attitudes. Thus, social learning theorists or the social constructionists as they are sometimes called believe that parents, as the distributors of reinforcement, reinforce appropriate gender role behaviors. By doing this, parents encourage children to engage in gender-appropriate behaviors. Children may also observe and internalize the specific gender role behaviors put up at home. Children may also observe too that societies have different expectations about how the two sexes should act.

The social learning theory also posits that people are not passive recipients of social roles and expectations concerning gender and gender roles. Instead, they are seen as active participants. I illustrate in this paper that girls largely engages in water hauling activities, compared to boys because this responsibility is socially constructed. Most often, many girls grow up seeing and observing their mothers and older girl siblings engaging in water hauling activities when water problems strike their homes. Also, as a cultural expectation, most girls assist their mothers and siblings in carrying out these activities. Thus, having directly and indirectly learned this, most girls grow up with this responsibilities or gender specific roles socially imprinted in their minds.

\section{Findings and Discussions}

\subsection{Age and Sex}

All the students sampled were girls at the junior high school in the Tamale metropolitan area. Out of this number, $73 \%$ were in their final year, $14 \%$ in the second year and $4 \%$ in the first year. The girls also hailed from different areas within the Metropolis. The data gathered indicated that 14 (23.3\%) hailed from Lamashegu, 8 (13.3\%) were from Nyohini, 6 (10\%) from Zogbeli, 3 (5\%) from Kakpagyili and 2 (3.3\%) each from Kaladan, Salamba and Agric areas. One 1 (1.7\%) each came from other areas such as New Town, Zujung, Ward K, T. Poly, Sawaba, Sagnarigu, Moshie Zongo, Gurigu, Filling Point, Education Ridge, Chogu, Chagli, Bagabaga and Aboabo.

On the part of the teachers and school authorities, they were made up of fifteen males and five females constituting 75\% and 25\% respectively. Two (10\%) were Assistant Headmasters, 17 (85\%) were subject masters with 1 (5\%) being a Guidance and Counseling Coordinator. Equally, the teachers and school authorities came from areas such 
as Nyohini (4), 2 each hailed from Lamakara, Lamashegu and Zogheli respectively while one each, came from other areas such as Hospital Road, Ward K, Builpela.

In terms of the ages of the girls, $73.3 \%$ belonged to the $15-17$ age group, $18.3 \%$ on the $12-14$ age group and $8.3 \%$ were above 18 years. This information was not surprising because under the new educational system introduced in 1988 , a child is expected to be in the junior high school by the age of fourteen. As indicated initially, 8.3 percent of the girls were above 18 years. This shows that the girls within this age category might have entered school late. In an interview with a teacher, it was gathered that some parents in the Metropolis do not still place premium on the girl-child in terms of education and so sometimes get them enrolled in school late. A head teacher indicated that some of these girls had earlier on completed the Junior High School (JHS), but could not pass the exams which would have enabled them to progress to the Senior High Schools (SHS) level. Some of them, though passed their exams, they could not proceed to the SHS because their parents could not afford to pay their fees.

\subsection{The Home Environment}

The study found that, $68 \%$ of the girls were staying with their parents with the remaining percentage but $1 \%$ not staying with their parents. The $1 \%$ could not offer responses to this question. Those not staying with their parents were making up with other relations such as their aunts, grandparents and uncles. This was expected because of the traditional foster system in the area, especially among Dagombas, Gonjas and Mamprusis, the three most dominant ethnic groups in the Tamale metropolis. As Goody (1973 in Imoh: 4) notes, among the Gonja, it is an obligation of parents to send their children either to the mother's brother or the father's sister depending on their sex. This system of foster, which was meant to ensure checks and balances as well as ensure the protection of children, imply that male children were sent to their mother's brother and female children to the father's sister. However, as UNICEF (2012) notes, child fosterage in Ghana remains one of the critical sociocultural factors hindering girls' education.

The study also looked at the number of people in the households where the girls hailed from. This was significant because the number of household members partly determines the quantity of water usage. The greater the number of members, the greater the workload or burden on girls when there is no water in the house. The study revealed that $71.7 \%$ of the girls were living with more than six people, $18.3 \%$ with four people and the remaining $10 \%$ staying with two people. As is the case with most Ghanaian homes, the girl-child do a large proportion of household chores, such as cooking, washing, sweeping and looking for water for household or domestic use. To the question as to which sex group often looks for water in the house, $92 \%$ responded that it is the girl-child whilst only $3 \%$ responded that it is the boy-child. Only $5 \%$ alluded to both sexes. Several reasons were assigned for this. An overwhelming $48(80 \%)$ of the girls see water hauling activities as their responsibility, $7(11 \%)$ see it as a task that is always forced on them with $2(3.3 \%)$ subscribing to other reasons, such as the perception that under customs and traditions, boys are not required to look for water for the house but to farm and do other masculine related tasks. The girls probably see water hauling activities as their tasks because of the gender role theory which socio-culturally condemns the girl-child to this responsibility. From birth, boys and girls are socialized to behave in "sex appropriate" ways, which is to conform to society's standards for acceptable maleness and feminine behaviours. This implies therefore that, society has structured itself by assigning certain responsibilities to its individual members based on sex. Though this is largely biologically driven, it is socially reinforced through observations and imitations etc. These rules, expectations, beliefs, feelings, and attitudes are largely responsible for the affirmation by the girls that it is their responsibility to look for water for household and other uses.

On the availability of needed water at home, the survey revealed that $65 \%$ of water needed is not always readily available. Accordingly, needed water is not readily available because either the residents gets water once a week (55\%), twice a week (15\%), not for a lengthily period or not at all (5\%). Only $18.3 \%$ of the girls responded that they have water every day. As an indispensable resource, people faced with the water crisis are compelled to search for it irrespective of the challenges that come with it, sometimes very daunting. Some of the respondents (45\%) are for instance compelled to walk 2-4km in search of this precious resource. Also, 20\% walk 5-7 km to look for water. In carrying out this responsibility of hauling for this treasured resource, quite a great amount of man hours are loss. For example, $25 \%$ of the girls spend less than an hour or an hour in their search, $23.3 \%$ spend two hours, $16.7 \%$ spend four hours and $10 \%$ spend three hours on the average. It was also identified that these times are most often spent during the day (48\%), at dawn (38.3\%) and at midnight (13.3\%). The combined percentage of those who fetches water at dawn and at night is $51.6 \%$, higher than those who fetch water during the day. This implies that the taps in the Metropolis starts running largely at night and at dawn which the girls must attend to before the taps stop running as this is usually short lived. Related to these, a key informant, emphasized thus: 
...you can see that these girls will not come to school early....because they have to look for water for the house...to bath, cook and if the parents are petty traders....they have to look for water to aid their businesses....

In other responses, some of the participants emphasized that the Ghana Water Company Limited (GWCL), which is mandated by law to manage and supply water to the inhabitants, was not doing enough in meeting its mandate as service providers. A key informant in an interview for instance emphasized that:

The GWCL is just wicked. They promised you every time and they fail all the time....unless they work well, this problem will remain for many years to come...

Because of the difficulty in meeting the mandate, the GWCL relies on rationing as a temporal measure. A large number of the respondents however argued that although a laudable short term measure, the rationing process has been ineffective. Some respondents for example indicated that the company is not always consistent with its rationing schedules/time table.

\subsection{Money Spent On Water and Its Effects}

In the wake of the difficulties in accessing water, it was discovered that households spend quite a lot of money to buy water from private suppliers. Data on this showed that 29 (48.3\%) of the households spend between 5-10 Ghana cedis on the average on water a week, 25\% spend between 20-30 Ghana cedis and 16.7\% notes that they spend 40-50 Ghana cedis and $10 \%$ spend over 70 Ghana cedis a week on water. Considering the average amount of incomes of the average Ghanaian, especially people from the northern region, noted as the third poorest region in Ghana, these amounts are very quite very huge expenditures. Most of the parents/guardians are found in the informal sector and so make little amounts monthly. During interviews, it was identified that some of the parents/guardians could not easily quantify their monthly incomes because they were said to be so meager that they are easily spent right away after they are received.

Added to this, most of the parents/guardians also have very large number of children and dependents (more stomachs to feed) to cater for. Thus spending such huge amounts of money were seen to be having negative effects in meeting other household responsibilities. Some of the net effects of this included the inability of parents/guardians to pay the girls' school fees (11.7\%), inability to buy the required books and other educational materials for their wards (48.3\%) and the inability to give their wards adequate money for school (16.7\%). All these have the final effect of negatively affecting the performance of their wards in school, especially girls. One significant effects of this was the fact girls from these backgrounds are often teased by their colleagues because they do not have certain basic things in school and have to depend on others, sometimes for food and money. Again, they also would have to depend on their colleagues for certain books and educational materials because of their parents'/guardians' inability to acquire these for them.

\subsection{Net Effects of Water Crisis on Girls' Education}

The research explored the overall effects of the water crisis on the education of girls in the Tamale area. Areas explored included effects on attendance/regularity, punctuality participation and performance. When the girls were asked about their regularity to school, $63 \%$ answered that they were regular to school. The remaining $31.7 \%$ were found to be irregular to school. They attributed their irregularity in part to the water hauling activities that they are always engaged in. In response to the same question however, teachers and school authorities noted that almost $65 \%$ of girls were not regular to school. Most of them referred to their engagement in other social and economic activities, domestic pressure (water hauling activities included), among others, as some of the overriding factors. Related to this, water related diseases and illnesses also contribute to school attendance and regularity. In this sense, it was essential to explore this aspect as well. It was identified that $50 \%$ of the teachers and school authorities noted they have had reported cases of water related diseases in their schools with guinea worm recording the highest reported case (30\%). This was followed by cholera (15\%). These cases negatively affected the attendance of students in school, including the girl-child. When the attendance data was cross-checked from the various class registers, it was identified that compared to boys, girls were irregular to school.

On punctuality, $55 \%$ of the girls noted that they were punctual to school whilst the remaining percentage of $45 \%$ answered that they were not punctual to school. They attributed their lateness largely to their domestic responsibilities of having to look for water for their households when the taps were not running. In response to the same question, the teachers noted that most of the girls do not abide by the reporting time to school, which is 7 am. They attributed this largely to the engagement of the girls in domestic duties for which water hauling activities are significant. This shows that 
the water shortage in the Metropolis is having a negative effect on the punctuality of the girl-child to school.

Whether the teachers and school authorities were punctual and regular to school themselves, the data gathered showed that with $90 \%$ of the teachers and school authorities faced with water crisis, this negatively affected their regularity (75\%) and punctuality (65\%) to school. As to how it negatively affected their output in class, $40 \%$ of them alluded to the fact that tiredness, resulting from regular search for water made them not to deliver very well in class because they were often ill prepared. Also, 15\% attributed it to the fact that they do not come to school at all after the hard day's search for water. As is usually the case in other studies, students, especially girls, most often fetch water for their teachers, particularly during water crisis. However, this survey rather showed a different picture. The survey indicated that $65 \%$ of the girls did not help the teachers and school authorities in the search for water. The effect of these on students' performance and for that matter the girl-child in this situation is anything but on the downside.

On participation and performance, and given the fact that the performance of girls at the JHS level in the Metropolis is dwindling over the years, affecting their transition to the SHS, it was significant to explore whether the perennial water problems in the area was partly responsible. Data gathered indicated that $20 \%$ of the teachers and school authorities saw the performance of the girls as encouraging and fair, $25 \%$ saw it as good and $35 \%$ saw it as poor. The teachers attributed the poor performance of the girls partly to their engagement in the search for water. According to most of them, a large number of the girls constantly engaged in the search for water, are most often irregular and late to school. They do not also participate actively in class (47\%), often feel sleepy in class when teaching is ongoing. Some of the teachers and school authorities also noted that most of the girls (47\%) fail to do their home works and assignments regularly because they have to always look for water after school. The net effect of all these is the poor performance of girls in school. The findings further points to the fact that most of the girls whose performance was encouraging were not consistent with their performance. This was attributed in part to their search for water since it gave them little time to study.

\section{Conclusions and Implications}

Considering the fact that water is life and that every socio-economic activities depend either directly or indirectly on water availability, situations whereby it becomes difficult to have access to it, as has always been the case in Tamale and other communities in Ghana, its effects on education in general, and girl child education in particular become worrying. To help meet these unending challenges, firstly, parents need to be educated on the need to completely have a second look at the responsibilities of the girl-child at home vis-vis that of the boy-child. Though, most girls see this responsibility of looking after water for the household and for other activities as a gender role that they must fulfill, this attitude need to be seriously reconsidered and possibly changed so that boys would equally play responsible roles in this direction, especially in the face of crises. Parents should equally endeavor to eliminate sex-role socialization practices. Children should be nurtured to take on the roles, attitudes and behaviors they desire and for which they have aptitudes and interests, rather than nurturing them based on their sexes. Parents should also learn to relate to each child as an individual, not as a male or a female.

Teachers and school authorities also have a role to play. Teachers and school authorities are repositories of knowledge and so hold the key to the successes of girls. They are equally admonished to adopt strategies that will enable them to finish up their syllabi on time. They are particularly admonished to find time off their busy schedules by organizing extra classes for the girls in order that they could finish up the various syllabuses.

Also, both the print and electronic media should also help to put an end to sex-role stereotyping through their programs (radio and television discussions by the electronic media and series of articles and editorials by the print media) by portraying females and males in a variety of roles-such as males performing domestic tasks and females being for instance pilots and physicians. Since the media are agenda setters, their role in this light have the tendency of enhancing significant changes in the society.

Without trying to downplay the efforts made in the past and being made today by successive governments to tackle the seemingly intractable problems in the water sector, a fast track, a multi-faceted and a comprehensive approach need to be adopted to overhaul the water sector. This is premised on the fact that the concept of good governance is essentially about improving the living standards of people in a polity. This involves the provision of the basic necessities of life for which water is one.

Finally, research has incontrovertibly indicated that one of the militating factors against the inconspicuous presence in decision-making by women is the lack of education which has directly affected their level of self-confidence and limited their self acceptance and assertiveness (Allah-Mensah, 2005). Education has long been accepted as one of 
the effective instruments through which the behaviour of an individual is redefined to conform to societal expectations. Functionally, education can be said to be necessary because it contributes to the survival of society. Education plays a critical role in human resource development, which is the foundation for nation building and essential for sustainable development, especially in developing countries. Education makes new persons out of individuals. The overall implication is therefore that, in order to close the yawning gap in decision-making, to break the culture of silence, sustain and consolidate the gains and successes chalked by girls and women in the education sector, anything that tries to inhibit it should be given utmost consideration and tackle forth with, including access to water.

\section{References}

Allah-Mensah, B. (2005). Women in Politics and Public Life in Ghana. Accra, Friedrich Ebert Stiftund.

Bank, B. J. (2007). Gender and Education: An Encyclopedia Volume I. London, Praeger Publishers.

Ghana Demographic and Health Survey (2008). Accra, Ghana Statistical Service.

Goody, E. (1982). 'Some Theoretical and Empirical Aspects of Parenthood in West Africa', in Imoh, A, T. (2012). From Central to Marginal? Changing Perceptions of Kinship Fosterage in Ghana. Journal of Family History 00(0) 1-13.

Henry, G. et'al. (1999). Psychology, W.W Norton and Company, Inc. New York

Herz, B. and Sperling, G. B. (2004). What works in girl's education: Evidence and

policies from the developing world. Montreal, Council on Foreign Relations.

Lloyd, C.B., Mensch, B.S and Clark, W.H. (1998). The effects of primary school quality on the educational participation and attainment of Kenyan boys and girls. New York, Population Council.

Republic of Ghana. 1992 Fourth Republican Constitution. Accra, Assemblies Press.

Sutherland-Addy, E. (2008). Gender equity in junior and secondary education in South-

Saharan Africa. World Bank Working Paper No 140. Africa Human Development Series. Washington, D.C.

Tanye, M. (2008). Access and barriers to education for Ghanaian women and girls. Interchange, Vol. 39/2, 167-184.

The women's manifesto for Ghana (2004). The coalition on the women's manifesto for Ghana. Accra, ABANTU for Development.

UNESCO (2004). Education for All: The quality imperative. EFA Global Monitoring

Report. Paris.

UNICEF (2012). All children in school by 2015. Global Initiative on out-of-school children: Ghana country study. UNICEF.

United Nations Development Programme (2006). Human Development Report. Beyond scarcity: Power, poverty and the global water crisis. New York, UNDP.

United Nations Organization. Convention on the Rights of the Child (1989). New York, UNO.

United Nations Organization. Universal declaration of human rights (1948). Dignity and justice for all of us: 60th anniversary edition. 
